DOI: $10.526 /$ cab.v14i3.23613

\title{
PARÂMETROS COMPORTAMENTAIS DE VACAS DE DESCARTE EM PASTAGENS DE MILHETO OU CAPIM SUDÃO
}

\author{
Rangel Fernandes PaCheCo ${ }^{1}$, Dari Celestino Alves Filho ${ }^{2}$, IVAN Luiz Brondani ${ }^{2}$, JoÃo \\ RESTLE $^{4}$, LUIZ ANGELO DAMIAN PIZZUTI ${ }^{2}$, JONATAS CATTELAM ${ }^{1}$ \\ ${ }^{1}$ Pós-graduandos, Universidade Federal de Santa Maria, Santa Maria, RS, Brasil. rangelzootec@hotmail.com \\ ${ }^{2}$ Professores Doutores, Universidade Federal de Santa Maria, Santa Maria, RS, Brasil. \\ ${ }^{3}$ Professor Visitante, Fundação Universidade Federal do Tocantins, Araguaína, TO, Brasil
}

Objetivou-se com este estudo avaliar os parâmetros comportamentais e as estratégias de deslocamento e alimentação de vacas de descarte em pastagens de milheto ou capim sudão. Os tratamentos consistiram em: pastagem de milheto (Pennisetum americanum (L.) Leeke) ou pastagem de capim sudão (Sorghum bicolor cv. sudanense), ambos tratamentos submetidos ao pastejo contínuo de vacas de descarte, ao longo de 63 dias experimentais, subdividido em três períodos. Foram utilizadas 20 vacas de descarte cruza Charolês x Nelore, de idade média de 8 anos e peso vivo médio inicial de 445 $\mathrm{kg}$. Os animais foram distribuídos em 10 piquetes, sendo utilizados cinco piquetes para cada tratamento comportando duas vacas. As avaliações comportamentais foram realizadas durante 24 horas ininterruptas. O delineamento experimental foi inteiramente casualizado com 2 tratamentos e 3 períodos de avaliação. O tempo de pastejo das vacas apresentou interação $(\mathrm{P}=0,0035)$ entre tratamento e período, sendo o menor tempo destinado à atividade no primeiro período na pastagem de milheto (504 minutos) comparado com o segundo período desse mesmo tratamento (587 minutos) e terceiro período nas pastagens de capim sudão (535 minutos). Os tempos de ruminação e ócio foram semelhantes entre os tratamentos; no entanto, o de ócio diminuiu e o de ruminação aumentou com o avanço dos períodos. As espécies de forrageiras não influenciaram as variáveis relacionadas às estratégias de deslocamento e alimentação. Com o avanço do ciclo das pastagens, o número de passos por minuto, estações por minuto e por dia diminuíram enquanto a taxa de bocado e número de bocados por dia aumentaram. Os parâmetros comportamentais de vacas de descarte em pastagens de milheto ou capim sudão são similares; no entanto, o avanço do ciclo vegetativo dessas espécies proporciona modificações no padrão comportamental dos animais.

PALAVRAS-CHAVE: estratégias de deslocamento; gramíneas; Pennisetum; Sorghum; taxa de bocado; tempo de pastejo.

\section{BEHAVIORAL PARAMETERS OF CULL COWS GRAZING MILLET OR SUDAN GRASS}

\section{ABSTRACT}

The objective of this study was to evaluate the behavioral parameters and strategies of displacement and feeding of cull cows grazing millet or sudan grass. The treatments consisted of: pearl millet (Pennisetum americanum (L.) Leeke) or sudan grass (Sorghum bicolor cv. Sudanense). Both treatments were submitted to continuous grazing of cull cows over 63 experimental days subdivided into three periods. Using 20 Charolais $\mathrm{x}$ Nellore cull cows, at the average age of 8 years and average weight of $445 \mathrm{~kg}$. The animals were divided into 10 paddocks, five paddocks used for each treatment comprising two cows. The behavioral assessments were carried out for 24 hours straight. The experimental design was completely randomized with two treatments and three periods. The grazing time of cows showed interaction $(\mathrm{P}=0.0035)$ between treatment and period, and the shortest time for 
the activity in the first period on pearl millet (504 minutes) compared to the second period of that same treatment (587 minutes) and the third period on sudan grass pastures (535 minutes). The times of rumination and idling were similar between treatments; however, the idling time decreased and rumination increased with time periods. The forage species did not affect the variables related to the strategies of displacement and feeding. With the advancement of cycle pastures the number of steps per minute, stations per minute and per day decreased while the bite rate and the number of bites per day increased. The behavioral parameters of cull cows grazing sudan grass or millet are similar; however, the advancement of the vegetative cycle of these species provides changes in the behavioral pattern of the animals.

KEYWORDS: bit rate; displacement strategies; grasses; grazing time; Pennisetum; Sorghum.

\section{INTRODUÇÃO}

Nas últimas décadas houve aumentos expressivos nos estudos voltados para as avaliações comportamentais de bovinos de corte, em diferentes sistemas de pastejo e com uma ampla variedade de espécies de gramíneas. Essas pesquisas permitiram grande evolução na compreensão das respostas de desempenho dos animais por parte da academia em função de manejo ou escolha de espécie de gramíneas para pastejo (KONDO, 2011).

No Brasil, inúmeras espécies de gramíneas de estação quente são comercializadas com o intuito de atender diferentes sistemas de produção. Dentre essas, o milheto e o capim sudão vêm sendo utilizadas para a alimentação de bovinos de corte. Enquanto a primeira é amplamente explorada em sistemas de pastejo contínuo, com características produtivas que a consolidam como forrageira de grande potencial produtivo (RESTLE et al., 2002; PILAU \& LOBATO, 2008), a segunda é recomendada para a formação de híbridos com sorgo, destinados a sistemas de pastejo rotativo (TAMELE, 2009) e regimes de corte (GONTIJO et al., 2008). Entretanto, esta última vem sendo utilizada em sistemas de pastejo contínuo no Rio Grande do Sul, em áreas onde tradicionalmente o milheto era explorado. O avanço do capim sudão para essas áreas é consequência da alta resistência a déficits hídricos da espécie, o que notoriamente vem ocorrendo em algumas regiões do estado, no período de verão.

Embora haja grande variedade de opções de forrageiras de estação quente com potencial de exploração na bovinocultura de corte, o volume de informações científicas relacionadas ao comportamento de fêmeas de descarte acerca de grande parte dessas gramíneas é escasso. Segundo SBRISSIA (2004), mudanças conceituais da pesquisa destinadas ao estudo com forrageiras de estação quente são necessárias e passam pela compreensão do caráter sistêmico e dinâmico do ecossistema da pastagem, de forma que os universos envolvidos e suas interações sejam, sempre que possíveis, considerados.

Características das pastagens de estação quente, como a espécie de gramínea utilizada nos sistemas de produção (ZANINE et al., 2006) e as condições relacionadas ao estágio de desenvolvimento e arquitetura das plantas, refletem de forma expressiva no comportamento dos animais. Segundo HODGSON (1990), essas características condicionam diferentes estratégias de deslocamento e de seleção da dieta de bovinos de corte em pastejo contínuo, as quais irão refletir nos seus desempenhos. BAGGIO et al. (2009) demonstraram que o comportamento dos animais em pastejo é um importante indicativo das condições nas quais se encontram as pastagens, o que, de forma direta, torna essas informações importantes ferramentas orientadoras de manejos e ao mesmo tempo atende demandas da sociedade, em relação ao bem-estar animal.

Nesse sentido, o presente trabalho objetivou analisar os parâmetros comportamentais e as estratégias de deslocamento de vacas de corte em pastagens de milheto ou capim sudão.

\section{MATERIAL E MÉTODOS}

O experimento foi desenvolvido no Setor de Bovinocultura de Corte do Departamento de Zootecnia da Universidade Federal de Santa Maria. A área experimental utilizada foi de 15 hectares, dividida em doze piquetes. Os tratamentos consistiam em: Milheto - animais mantidos em pastejo contínuo de pastagem de milheto - e Sudão - animais mantidos em pastejo contínuo de pastagens de capim sudão. O método de pastejo foi o contínuo, com lotação variável.

Para a avaliação dos parâmetros comportamentais, foram utilizadas 20 vacas de descarte cruza Charolês x Nelore. Ao início do experimento, os animais apresentavam peso vivo médio de $445 \mathrm{~kg}$ e idade média de 8 anos. 
Para a manutenção da massa de forragem foram utilizados, quando necessário, animais reguladores. A massa de forragem (MF) foi estimada a partir da técnica de estimativa visual com dupla amostragem (WILM et al., 1944), no início do período de pastejo e a cada 10 dias, com vinte estimativas visuais e cinco cortes. Em cada corte, foi retirada uma amostra que, posteriormente, foi homogeneizada e dividida em duas sub-amostras, uma para a determinação do teor de matéria parcialmente seca do pasto (MPS) e outra para a separação manual dos componentes estruturais e botânicos da pastagem. Após a separação botânica e secagem dos componentes estruturais da pastagem, foi determinada a participação percentual de lâminas foliares, colmos, material morto das espécies alvo do estudo e espécies indesejadas. A partir da proporção de folhas e colmos foi determinada a relação folha:colmo. Para a determinação da oferta de forragem (OF), foi calculada a razão da $\mathrm{MF}$ disponível pela carga animal, sendo expressa como $\mathrm{kg}$ de MS/100 $\mathrm{kg}$ de peso vivo/dia (SOLLENBERGER et al., 2005). A oferta de lâminas foliares verdes (OFL) foi determinada através do produto da OF pelo percentual de lâminas foliares da MF.

As avaliações dos parâmetros comportamentais foram realizadas em três períodos, com avaliações em 10/02/2011 (1-21), 03/03/2011 (22-42) e 22/03/2011 (43-63), tomadas durante 24 horas ininterruptas. O delineamento experimental foi o inteiramente casualizado, com medidas repetidas no tempo, em arranjo fatorial 2 x 3 (dois tratamentos e três períodos), com 10 repetições (animais).

Os registros das atividades foram realizados por avaliadores treinados em número de 1 avaliador para cada 4 vacas, a cada 10 minutos, com a identificação da atividade de: pastejo (TP), ócio (TO) ou ruminação (TR), com auxílio de cronômetro e lanternas do tipo leed, para o período noturno. O tempo de pastejo foi considerado o período no qual o animal realizava a apreensão da forragem com pequenos deslocamentos; o tempo de ruminação foi considerado o período em que o animal não estava pastejando, porém estava mastigando o bolo alimentar regurgitado; para o ócio foi considerado o período em que o animal não estava pastejando ou ruminando, podendo estar incluídas atividades sociais e ingestão de água.

A taxa de bocado (TXboc) foi determinada durante as atividades de pastejo, com a tomada do máximo possível de atividades de taxa de bocado durante as 24 horas de avaliações, com o auxílio de cronômetros. Para a determinação da taxa de bocado, foi considerado o tempo gasto pelo animal para realizar 20 bocados e, posteriormente, foi corrigido para um minuto. Durante as atividades de pastejo ainda foram registrados o tempo e o número de passos que as vacas utilizavam para percorrer 10 estações alimentares. Cada estação alimentar foi identificada quando o animal encontrava-se em pastejo, sem movimentos das patas dianteiras, porém podendo ocorrer movimento da cabeça.

As variáveis número de passos por estação alimentar ( $\mathrm{N}^{\circ}$ Passos/est) foi calculada a partir da razão do número de passos médio por estação por 10; número de estações por minuto $\left(\mathrm{N}^{\circ}\right.$ Estações $/ \mathrm{min})=60 * 10 /($ tempo médio para percorrer dez estações); número de estações diárias ( $\mathrm{N}^{\circ}$ estações/dia) pelo produto do tempo de pastejo pelo $\mathrm{N}^{\mathrm{o}}$ Estações/min; número de passos por minuto $\left(\mathrm{N}^{\circ}\right.$ Passos $\left./ \mathrm{min}\right)$ pelo produto do $\mathrm{N}^{\circ}$ Passos/est pelo $\mathrm{N}^{\circ}$ Estação/min; número de passos dia ( $\mathrm{N}^{\circ}$ Passos/dia) através do produto do tempo de pastejo pelo $\mathrm{N}^{\circ}$ Passos/min; a taxa de bocados por dia $\left(\mathrm{N}^{\circ}\right.$ Bocados/dia) foi determinada pelo produto da TXboc pelo tempo de pastejo.

Todas as variáveis foram submetidas a teste de normalidade pelo teste Shapiro-Wilk, sendo realizadas as seguintes transformações quando necessário: $\mathrm{N}^{\mathrm{o}}$ Passos entre estações $(1 /(\mathrm{x})), \mathrm{N}^{\mathrm{o}}$ Passos/min $(\log (\mathrm{x})), \mathrm{N}^{\mathrm{o}}$ estações/min $(\log (\mathrm{x})), \mathrm{N}^{\mathrm{o}}$ estações/dia $(\log (\mathrm{x}))$, número de bocados/dia $(\log (\mathrm{x}))$. Posteriormente foram realizadas análises de variância e teste $\mathrm{F}$, em nível de $5 \%$ de significância, utilizando-se o PROC MIXED (modelos mistos).

O MIXED foi utilizado devido à natureza das medidas repetidas dos dados (sequencialmente no tempo). Esse procedimento fornece maiores classificações de tipos de matrizes de covariância a serem selecionadas. O critério de informação para a melhor estrutura de variância foi pelo menor valor de AIC. As médias entre os tratamentos foram submetidas à análise de variância e teste " $t$ " de Student, em nível de 5\% de significância, utilizando-se o "LSMEANS". Foram detectados os efeitos da causa de variação principal (espécie e período), assim como as interações entre elas. As análises dos dados foram realizadas com o auxílio do pacote estatístico SAS versão 8,01 .

Nas Tabelas 1 e 2 são apresentados os valores observados para as características produtivas das pastagens, em função dos tratamentos e períodos de avaliação. 
Tabela 1 - Características produtivas das pastagens de milheto ou capim sudão

\begin{tabular}{lcc}
\hline & \multicolumn{2}{c}{ Tratamentos } \\
\cline { 2 - 3 } Variáveis & Milheto & Sudão \\
\hline MS (g/kg de MV) & 222,0 & 233,9 \\
PB (g/ kg de MS) & 136,1 & 130,6 \\
FDN (g/ kg de MS) & 523,4 & 505,7 \\
Massa de Forragem (kg de MS/ha) & 1606,93 & 1617,47 \\
Oferta de Forragem (kg de MS/100kg de PV) & 9,42 & 8,29 \\
OFL (kg de MS/100kg de PV) & 2,79 & 2,43 \\
Relação de folha e colmo & 0,76 & 0,78 \\
Espécies indesejadas (g/kg de MS) & 483,81 & 455,89 \\
\hline
\end{tabular}

Tabela 2 - Características produtivas das pastagens de milheto ou capim sudão em função dos períodos de avaliação

\begin{tabular}{lcccc}
\hline Variável & \multicolumn{3}{c}{ Períodos (dias) } & \\
\cline { 2 - 4 } & $1^{\circ}-21^{\circ}$ & $22^{\circ}-42^{\circ}$ & $43^{\circ}-63^{\circ}$ & Média \\
\hline MS (g/kg de MV) & 215,6 & 216,5 & 250,4 & 227,5 \\
PB (g/kg de MS) & 170,4 & 129,6 & 100,1 & 133,4 \\
FDN (g/ kg de MS) & 488,1 & 490,1 & 565,4 & 514,5 \\
Massa de Forragem (kg de MS/ha) & 1514,6 & 1748,8 & 1568,7 & 1610,7 \\
Oferta de Forragem (kg de MS/100kg de PV) & 9,23 & 8,11 & 9,21 & 8,85 \\
OFL (kg de MS/100kg de PV) & 3,63 & 1,98 & 2,23 & 2,61 \\
Relação de folha e colmo & 1,15 & 0,58 & 0,57 & 0,77 \\
\hline
\end{tabular}

O modelo matemático utilizado para análise de variância foi:

$Y_{i j k}=\mu+T_{i}+R_{k}\left(T_{i}\right)+P_{j}+(T P)_{i j}+e_{i j k}$

Considerando: $\mathrm{Y}_{\mathrm{ijk}}$ representa as variáveis dependentes; $\mu$, a medida de todas as observações; $\mathrm{T}_{\mathrm{i}}$, o efeito do i-ésimo tratamento alimentar; $\mathrm{R}_{\mathrm{k}}\left(\mathrm{T}_{\mathrm{i}}\right)$, o efeito da k-ésima repetição dentro do i-ésimo tratamento (erro a); $\mathrm{P}_{\mathrm{j}}$, o efeito do j-ésimo período; $(\mathrm{TP})_{\mathrm{ij}}$, a interação entre o i-ésimo tratamento e o jésimo período; e $\mathrm{e}_{\mathrm{ijk}}$, o erro experimental total (erro b).

Tabela 3 - Tempo de pastejo de vacas de descarte em fase de terminação em pastejo contínuo em pastagens de milheto ou capim sudão

\begin{tabular}{|c|c|c|c|c|c|c|}
\hline \multirow{3}{*}{ Tratamentos } & \multicolumn{3}{|c|}{ Tempo de pastejo (minutos/dia) } & \multirow{3}{*}{ Média } & \multirow{3}{*}{ Erro-Padrão } & \multirow{3}{*}{$\begin{array}{c}\text { Probabilidade } \\
\text { Trat. x Per. }\end{array}$} \\
\hline & \multicolumn{3}{|c|}{ Período (dias) } & & & \\
\hline & $1^{\circ}-21^{\circ}$ & $22^{\circ}-42^{\circ}$ & $43^{\circ}-63^{\circ}$ & & & \\
\hline Milheto & $504^{b}$ & $587^{\mathrm{a}}$ & $578^{\mathrm{ab}}$ & 557 & 25,24 & 0,0395 \\
\hline Sudão & $566^{\mathrm{ab}}$ & $559^{\mathrm{ab}}$ & $648^{\mathrm{a}}$ & 591 & & \\
\hline Média & 535 & 573 & 613 & & & \\
\hline
\end{tabular}

\section{RESULTADOS E DISCUSSÃO}

Houve interação entre tratamento $\mathrm{x}$ período para a atividade de pastejo (Tabela 3 ). Os animais demonstraram menores tempos destinados à atividade de pastejo no primeiro período de avaliação comportamental nas pastagens de milheto, quando comparado ao segundo período desse mesmo tratamento e ao terceiro do tratamento Sudão. Nas demais comparações das médias, independentemente de período ou tratamento, o tempo destinado à atividade de pastejo foram semelhantes.

Letras minúsculas diferem entre linhas e colunas pelo teste "t" a 5\% de significância. 
O aumento no tempo de pastejo das vacas era esperado com o avançar do ciclo das pastagens, como forma de compensar às reduções da qualidade e disponibilidade de alimento das pastagens com o avanço do ciclo vegetativo. Isso ocorreu em função do processo de lignificação das gramíneas, gradativo com o avançar de seu ciclo, e principalmente pela redução da disponibilidade e, por consequência, da acessibilidade às lâminas foliares, confirmadas pelas correlações negativas da variável tempo de pastejo com a oferta de lâminas foliares e relação de folha:colmo, $\quad(\mathrm{r}=-0,32 ; \mathrm{P}=0,0127$ e $\mathrm{r}=-0,38$; $\mathrm{P}=0,030$; respectivamente). Segundo WOODWARD (1997), à medida que a capacidade de seleção da dieta por parte dos bovinos diminui, os animais aumentam a taxa de bocados e o tempo de pastejo, como mecanismo de compensação de reduções no tamanho do bocado realizado.

Além de características quantitativas, as características qualitativas, como os teores de proteína bruta $(\mathrm{PB})$ e fibra em detergente neutro (FDN), também podem afetar o comportamento ingestivo dos animais (MANZANO et al., 2007).
Nos estudos de BRÂNCIO et al. (2003), os autores não observaram correlações do tempo de pastejo de novilhos com características quantitativas das pastagens de três cultivares de Panicum maximum (Mombaça, Massai e Tanzânia), manejadas em sistema de pastejo rotacionado; no entanto, os autores verificaram correlações com as características qualitativas das pastagens, como o teor de lignina ao início da ocupação dos piquetes e ao final do ciclo da pastagem, de forma negativa com os teores de $\mathrm{PB}$ e digestibilidade. No presente estudo, o tempo de pastejo se correlacionou negativamente com o teor de PB da pastagem ( $\mathrm{r}=$ $0,29 ; \mathrm{P}=0,0238)$, não apresentando correlação com $\mathrm{FDN}(\mathrm{r}=0,15 ; \mathrm{P}=0,2614)$.

O tempo de ruminação e ócio não diferiu significativamente entre os tipos de pastagens utilizadas na terminação das vacas de descarte (Tabela 4). Esse comportamento era esperado, uma vez que as características produtivas e bromatológicas das pastagens também foram similares em função da espécie das gramíneas (Tabela 1).

Tabela 4 - Tempos de ruminação ou ócio (em minutos/dia) de vacas de descarte em fase de terminação em pastagens de milheto ou capim sudão

\begin{tabular}{|c|c|c|c|c|}
\hline \multirow{2}{*}{ Variáveis } & \multicolumn{2}{|c|}{ Tratamentos } & \multirow[b]{2}{*}{ Erro-Padrão } & \multirow[b]{2}{*}{$\mathrm{P}$} \\
\hline & Milheto & Sudão & & \\
\hline Ruminação & 305 & 318 & 12,28 & 0,4526 \\
\hline Ócio & 578 & 531 & 2,86 & 0,1079 \\
\hline
\end{tabular}

Quanto às avaliações dos tempos de ruminação e ócio em função dos períodos de avaliação, foi possível verificar mudanças com o avanço do ciclo vegetativo das pastagens (Tabela 5). Como discutido anteriormente, características quantitativas e qualitativas das pastagens fizeram com que o tempo destinado ao pastejo dos animais aumentasse com o avanço dos períodos de avaliação. Essa tendência fez com que os tempos de ruminação $(242,295$ e 389 minutos) aumentassem, enquanto os de ócio (662, 565 e 435 minutos) diminuíssem $(\mathrm{P}<0,0001)$. $\mathrm{O}$ teor de FDN da pastagem correlacionou-se positivamente com o tempo de ruminação $(r=0,47 ; \mathrm{P}<0,0001)$ e negativamente com o tempo de ócio $(\mathrm{r}=-0,42 ; \mathrm{P}=0,0008)$. Esse comportamento, embora esperado, não é desejado, uma vez que o aumento do tempo de ruminação associado com o de pastejo implica em maior gasto energético.

Tabela 5 - Tempo de ruminação ou ócio (em minutos/dia) de vacas de descarte em fase de terminação em relação ao período de avaliação

\begin{tabular}{|c|c|c|c|c|c|c|}
\hline \multirow[t]{2}{*}{ Variáveis } & \multicolumn{3}{|c|}{ Períodos (dias) } & \multicolumn{2}{|r|}{ Erro- } & \multirow[b]{2}{*}{ Probabilidade } \\
\hline & $1^{\circ}-21^{\circ}$ & $22^{\circ}-42^{\circ}$ & $43^{\circ}-63^{\circ}$ & Média & Padrão & \\
\hline Ruminação & $242^{\mathrm{c}}$ & $301^{\mathrm{b}}$ & $392^{\mathrm{a}}$ & 312 & 18,12 & $<0,0001$ \\
\hline Ócio & $663^{\mathrm{a}}$ & $566^{\mathrm{b}}$ & $435^{\mathrm{c}}$ & 555 & 24,57 & $<0,0001$ \\
\hline
\end{tabular}

Letras maiúsculas diferem entre linhas pelo teste "t" a 5\% de significância. 
Observa-se na Tabela 6 que a utilização de pastagem de milheto ou capim sudão não alterou o número de estações alimentares $(8,69$ e 8,17 por minuto, respectivamente) e a taxa de bocados $(36,82$ e 35,88 por minuto, respectivamente). As semelhanças nas características quantitativas e qualitativas das pastagens, assim como as de desempenho das vacas em função dos tratamentos (PACHECO, 2013), estenderam-se também para as variáveis relacionadas aos parâmetros comportamentais. Características como composição botânica das pastagens (ARNOLD \& DUDZINSKY, 1967), estádio vegetativo (HODGSON, 1990) e disponibilidade e acessibilidade de folhas (ROGUET et al., 1998) estão dentre as principais características que afetam as estratégias de alimentação de bovinos, em pastejo contínuo. Quando essas características demonstram semelhanças, estendem-se também ao comportamento ingestivo dos animais (HODGSON, 1990). BRÂNCIO et al. (2003) observaram semelhanças no comportamento ingestivo de bovinos em função da cultivar da espécie forrageira de Panicum maximum Jacq. (Tanzânia, Mombaça ou
Massai), utilizada para pastejo, e também verificaram poucas diferenças nas variáveis taxas de bocado em quatro períodos de avaliações (junho, setembro, novembro e março). AURELIO et al., (2007) verificaram que mudanças estruturais das pastagens de Tifton 85 (Cynodon dactylon $\mathrm{x}$ C.nlemfuensis) ou capim elefante anão (Pennisetum purpureum cv. Mott) condicionam mudanças no número de estações alimentares por minuto em vacas leiteiras; no entanto, essas diferenças não se estenderam para o número de bocados por minuto.

O número de passos por minuto, número de estações por minuto e número de estações por dia, foram maiores no primeiro período de avaliação $(8,8$; 10,9 e 4780 , respectivamente) em relação ao segundo $(6,1 ; 8,0$ e 3445 , respectivamente) e terceiro período de avaliação $(5,2 ; 6,4$ e 3176 , respectivamente) (Tabela 7), sendo essas variáveis semelhantes nos dois últimos períodos. Já o número de passos entre as estações alimentares $(1,24 ; 1,30$ e $1,27)$ foi similar $(\mathrm{P}=0,8578)$ entre os períodos de avaliação.

Tabela 6 - Estratégias de deslocamento e consumo de vacas de descarte em fase de terminação em pastagens de milheto ou capim sudão

\begin{tabular}{|c|c|c|c|c|}
\hline \multirow[t]{2}{*}{ Variáveis } & \multicolumn{2}{|c|}{ Tratamentos } & \multirow[b]{2}{*}{ EP } & \multirow[b]{2}{*}{$\mathrm{P}$} \\
\hline & Milheto & Sudão & & \\
\hline $\mathrm{N}^{\circ}$ Passos/minuto & 6,61 & 6,76 & 0,47 & 0,9070 \\
\hline $\mathrm{N}^{\mathrm{o}}$ Passos entre estações & 1,32 & 1,23 & 0,06 & 0,2992 \\
\hline $\mathrm{N}^{\circ}$ Estações/minuto & 8,69 & 8,17 & 0,74 & 0,6706 \\
\hline $\mathrm{N}^{\mathrm{o}}$ Estações/dia & 3626 & 3975 & 296,33 & 0,4732 \\
\hline Taxa de bocados/minuto & 36,82 & 35,88 & 1,53 & 0,6698 \\
\hline Taxa de bocados/dia & 20820 & 21426 & 1036 & 0,6174 \\
\hline
\end{tabular}

As tendências observadas para o número de passos entre as estações alimentares e o número de estações alimentares/minuto não corroboram com o que é reportado na literatura. No presente trabalho, as ofertas de lâminas foliares e a relação folha colmo foram superiores no primeiro período de avaliação, seguidas de reduções drásticas nos períodos subsequentes (Tabela 2), comportamento esse que condicionaria maiores números de passos entre as estações alimentares (PALHANO et al., 2006; TEIXEIRA et al., 2010) e maior número de estações alimentares visitadas (PALHANO et al., 2006; BAGGIO et al., 2009).

Segundo BAGGIO et al. (2009), o tempo de permanência em uma estação alimentar se relaciona com a abundância de forragem, de forma que quanto maior a oferta de forragem na estação alimentar maior o tempo de permanência nela. Esses autores complementam que, embora não tenham observado diferenças para o número de passos, verificaram que a variável se correlacionou negativamente com a oferta de forragem $(\mathrm{r}=-0,57 ; \mathrm{P}=0,0033)$. Essa estratégia permite que o animal avalie melhor o ambiente alimentar disponível, disponibilizando mais tempo para a procura de melhores sítios de pastejo (ROGUET et al., 1998). A possível explicação para a similaridade no número de passos entre as estações alimentares e redução no número de passos e de estações alimentares/minuto com o avanço dos períodos de avaliação, no presente estudo, é o aumento da participação da espécie invasora Capim-papuã (Urochloa plantaginea), que 
passou a apresentar maior participação na composição botânica das espécies indesejadas da pastagem (PACHECO, 2013) e a redução da oferta de lâminas foliares.

Possivelmente, as mudanças ocorridas na composição botânica das pastagens tenham refletido em reduções da profundidade e volume de bocado das vacas, devido ao hábito de crescimento do capim papuã (cespitoso prostrado) (PACHECO, 2013) e da redução da participação de folhas na composição estrutural das pastagens. Isso fez com que os animais compensassem a redução do volume do bocado pelo aumento da taxa de bocados (Tabela 7), com consequência no tempo de procura por melhores estações de pastejo em função da necessidade de manter o nível de consumo de forragem, uma vez que a oportunidade de seleção, nessa situação, encontrava-se comprometida. REGO et al. (2006) demonstraram que a taxa de consumo instantânea em pastagens de estação quente é intensificada pela maior altura da pastagem; entretanto, os autores sugerem que as características do bocado são influenciadas pela estrutura da pastagem. Esses autores demonstraram que pastagens exclusivamente com leguminosas, com diferentes hábitos de crescimento, proporcionam aumento na taxa de bocado e menor tempo de manipulação do bocado, enquanto que em pastagens exclusivamente com gramíneas de estação quente há aumento na ingestão por bocado. Os coeficientes de correlação entre o número de passos por minuto com espécies indesejadas, oferta de lâminas foliares e relação folha:colmo apresentaram valores de: $\mathrm{r}=-0,45$ $(\mathrm{P}=0,0003) ; \mathrm{r}=0,25 \quad(\mathrm{P}=0,06)$ e $\mathrm{r}=0,23 \quad(\mathrm{P}=0,08)$, respectivamente; enquanto em relação ao número de estações por minuto foram de $\mathrm{r}=-0,39(\mathrm{P}=0,0021)$; $r=0,29 \quad(0,0233) \quad$ e $\quad r=0,29 \quad(P=0,0228)$, respectivamente.

Tabela 7 - Estratégias de deslocamento e consumo de vacas de descarte em fase de terminação em relação ao período de avaliação

\begin{tabular}{lllllll}
\hline Variáveis & \multicolumn{3}{c}{ Períodos (dias) } & & \\
\cline { 2 - 5 } & $1^{\mathrm{o}}-21^{\mathrm{o}}$ & $22^{\mathrm{o}}-42^{\mathrm{o}}$ & $43^{\mathrm{o}}-63^{\mathrm{o}}$ & Média & EP & $\mathrm{P}$ \\
\hline $\mathrm{N}^{\mathrm{o}}$ Passos/minuto & $8,8^{\mathrm{a}}$ & $6,1^{\mathrm{b}}$ & $5,2^{\mathrm{b}}$ & 6,7 & 0,50 & $<0,0001$ \\
$\mathrm{~N}^{\mathrm{o}}$ Passos entre estações & 1,24 & 1,30 & 1,27 & 1,27 & 0,07 & 0,8413 \\
$\mathrm{~N}^{\mathrm{o}}$ Estações/minuto & $10,9^{\mathrm{a}}$ & $8,0^{\mathrm{b}}$ & $6,4^{\mathrm{b}}$ & 8,43 & 1,17 & 0,0005 \\
$\mathrm{~N}^{\mathrm{o}}$ Estações/dia & $4780^{\mathrm{a}}$ & $3445^{\mathrm{b}}$ & $3176^{\mathrm{b}}$ & 3800 & 344 & 0,0097 \\
Taxa de bocado/minuto & $26,08^{\mathrm{c}}$ & $35,56^{\mathrm{b}}$ & $47,41^{\mathrm{a}}$ & 36,35 & 1,43 & $<0,0001$ \\
Taxa de bocado/dia & $13791^{\mathrm{c}}$ & $20507^{\mathrm{b}}$ & $29070^{\mathrm{a}}$ & 21123 & 1073,33 & $<0,0001$ \\
\hline
\end{tabular}

Letras maiúsculas diferem entre linhas pelo teste " $t$ " a $5 \%$ de significância.

A taxa de bocados por minuto $(26,08 ; 35,56$ e 47,41) e o número de bocados por dia (13791; 20507 e 29070) aumentaram $(\mathrm{P}<0,0001)$ com o avanço dos períodos de avaliação. Os menores valores de taxa de bocado no primeiro período podem ser associados à maior disponibilidade de folhas nos dosséis das pastagens. TEIXEIRA et al. (2011) demonstraram que, em pastagens com abundância de forragem, a taxa de bocados pode ser reduzida, uma vez que o animal consegue aumentar a profundidade e o volume de bocado e, consequentemente, diminuir a taxa de bocados.

Com o avanço dos períodos e consequente redução na oferta de lâminas foliares, e possível redução no volume de bocado das vacas, houve aumento gradativo na taxa de bocados, de forma que essa estratégia agisse como atividade compensatória a uma possível redução do volume de bocado, com o intuito de manter o nível de consumo de forragem, como discutido anteriormente. Comportamento esse justificado pela correlação negativa da taxa de bocados/minuto $(\mathrm{r}=-0,28$ e $\mathrm{P}=0,029 ; \mathrm{r}=-0,36$ e $\mathrm{P}=0,0048$, respectivamente) e taxa de bocados/dia $(\mathrm{r}=-0,32$ e $\mathrm{P}=0,0116 ; \mathrm{r}=-0,43$ e $\mathrm{P}=0,0006$; respectivamente) com a oferta de lâminas foliares $\mathrm{e}$ relação de folha:colmo. No entanto, cabe ressaltar que a estratégia de aumentar o número de bocados por minuto como compensação à redução no volume de bocado resulta em maior gasto de energia por unidade de matéria seca consumida (UNGAR et al., 1991). Um maior volume de bocado é mais interessante ao animal em função do menor gasto energético por kg de MS ingerida.

\section{CONCLUSÕES}

A utilização de pastagens de milheto ou de capim sudão não altera os parâmetros comportamentais e as estratégias de deslocamento e alimentação de fêmeas de descarte. Entretanto, o ciclo vegetativo altera as estratégias de alimentação e consumo, as quais, por sua vez, estão intimamente 
associadas às características produtivas das pastagens.

\section{REFERÊNCIAS}

ARNOLD, G.W.; DUDZINSKY, M.L. Studies on the diet of grazing animals: III. The effect of pasture species and pasture structure on the herbage intake of sheep. Australian Journal of Agricultural Research, v. 18, n.5, p. 657-666, 1967.

AURELIO, N.D.; QUADROS, F.L.F.; MAIXNER, A.R.; ROSSI, G.E.; DANIEL, E.; ROMAN, J.; BANDINELLI, D.G.; TRINDADE, J.P.P.; BRUM, M.S. Comportamento ingestivo de vacas holandesas em lactação em pastagens de capimelefante anão (Pennisetum purpureum cv. Mott) e Tifton 85 (Cynodon dactylon x C. nlemfuensis) na região noroeste do Estado do Rio Grande do Sul. Ciência Rural, v. 37 , n. 2, p. 470-475, 2007.

BAGGIO, C.; CARVALHO, P.C.F.; SILVA, J.L.S.; ANGHINONI, I.; LOPES, M.L.T.; THUROW, J.M. Padrões de deslocamento e captura de forragem por novilhos em pastagem de azevém-anual e aveia-preta manejada sob diferentes alturas em sistema de integração lavoura-pecuária. Revista Brasileira de Zootecnia, v.38, n.2, p. 215-222, 2009.

BRÂNCIO, P.A.; EUCLIDES, V.P.B.; NASCIMENTO JUNIOR, D.; FONSECA, D.M.; ALMEIDA, R.G.; MACEDO, M.C.M.; BARBOSA, R.A. Avaliação de três cultivares de Panicum maximum Jacq. sob pastejo: comportamento ingestivo de bovinos. Revista Brasileira de Zootecnia, v. 32, p. 1045-1053, 2003.

GONTIJO, M.H.R.; BORGES, A.L.C.; GONÇALVES, L.C.; RODRIGUES, J.A.S.; GOMES, S.P.; RODRIGUEZ, N.M.; CAMPOS, M.M. Potencial forrageiro de seis híbridos de sorgo com capim sudão. Revista Brasileira de Milho Sorgo, v. 7, n.1, p. 33-43, 2008.

HODGSON, J. Grazing Management. Science into Practice. New York: John Wiley e Sons. (Longman Handbooks in Agriculture), 203pp. 1990.

KONDO, S. Recent progress in the study of behavior and management in grazing cattle. Animal Science Journal, v. 82 , p. 26-35, 2011.

MANZANO, R.P.; NUSSIO, L.G.; CAMPOS, F.P.; ANDREUCCI, M.P.; COSTA. Comportamento ingestivo de novilhos sob suplementação em pastagens de Capimtanzânia sob diferentes intensidades de desfolhação. Revista Brasileira de Zootecnia, v. 36, p. 550-557, 2007.

PACHECO, R.F. Parâmetros produtivos e morfogênicos de pastagens de milheto ou capim sudão em pastejo de vacas de descarte. Dissertação (Mestrado em Zootecnia) - Programa de Pós-Graduação em Zootecnia, Santa Maria-RS. 139 pp. 2013. Disponível em: http://cascavel.cpd.ufsm.br/tede/index.php

PALHANO, A.L.S.; CARVALHO, P.C.F.; DITTRICH, J.R.; MORAES, A.; SILVA, S.C.; MONTEIRO, A.L.G. Padrões de deslocamento e procura por forragem de novilhas leiteiras em pastagem de capim-mombaça. Revista Brasileira de Zootecnia, v.35, p.2253-2259, 2006.

PILAU, A.; LOBATO, J.F.P. Manejo de novilhas prenhes aos 13/15 meses de idade em sistemas a pasto. Revista Brasileira de Zootecnia, v. 37, n.7, p. 1271-1279, 2008.

REGO, F.C.A.; DAMASCENO, J.C.; FUKUMOTO, N.M.; CÔRTES, C.; HOESHI, L.; MARTINS, E.N.; CECATO, U. Comportamento ingestivo de novilhos mestiços em pastagens tropicais manejadas em diferentes alturas. Revista Brasileira de Zootecnia, v. 35, n.4, p.1611-1620, 2006.

RESTLE, J.; ROSO, C.; AITA, V.; NORNBERG, J.L.; BRONDANI, I.L.; CERDÓTES, L.; CARRILO, C.O. Produção animal em pastagem com gramíneas de estação quente. Revista Brasileira de Zootecnia, v. 31, n.3, p. 1491-1500, 2002 (Supl.).

ROGUET, C.; DUMONT, B.; PRACHE, S. Selection and use of feeding sites and feeding stations by herbivores: a review. Annes de Zootechnie, v. 47, p. 225-244, 1998.

SBRISSIA, A.F. Morfogênese, dinâmica do perfilhamento e do acúmulo de forragem de capimmarandu sob lotação contínua. Tese (Doutorado em Agronomia) ESALQ/USP. - Escola Superior de Agricultura "Luiz de Queiroz", Piracicaba-SP. 171p. $2004 . \quad$ Disponível em: http://www.teses.usp.br/teses/disponiveis/11/11139/tde25052004-143513/pt-br.php

SOLLENBERGER, L.E.; MOORE, J.E.; ALLEN, V.G.; PEDREIRA, C.G.S. Reporting forage allowance in grazing experiments. Crop Science, v. 45, p. 896-900, 2005.

TAMELE, O.H. Manejo de híbridos de sorgo e cultivares de milheto em sistema de pastejo rotativo. Dissertação (Mestrado). Faculdade de Ciências Agrárias e Veterinárias - UNESP, Jaboticabal. 72pp. 2009. Disponível em: http://www.fcav.unesp.br/download/pgtrabs/zoo/m/80265. pdf

TEIXEIRA, F.A.; MARQUES, J.A.; SILVA, F.F.; PIRES, A.J.V. Comportamento ingestivo e padrão de deslocamento de bovinos em pastagens tropicais. Archivos de Zootecnia, v. 59(R), p. 57-70, 2010.

TEIXEIRA, F.A.; BONOMO, P.; PIRES, A.J.V.; SILVA, F.F.; MARQUES, J.A.; JÚNIOR, H.A.S. Padrões de 
deslocamento e permanência de bovinos em pastos de Brachiaria decumbens diferidos sob quatro estratégias de adubação. Revista Brasileira de Zootecnia, v. 40, n.7, p.1489-1496, 2011.

UNGAR, E.D.; GENIZI, A.; DEMMENT, M.W. Bite dimensions and herbage intake by cattle grazing short hand constructes swards. Agronomy Journal, v. 83, n. 6, p. 973-978, 1991.

WILM, H.G.; COSTELLO D.F.; KLIPPLE G.E. Estimating forage yield by the double sampling method. Journal Animal Society Agronomy, v. 36, p. 194-203,
1944.

WOODWARD, J.R. Formulae for predicting animal daily intake of pasture and grazing time from bite weight and composition. Livestock Production Science, v. 52, p.1-10, 1997.

ZANINE, A.M., SANTOS, E.M.; PARENTE, H.N.; FERREIRA, D.J.; CECON, P.R. Comportamento ingestivo de bezerros em pastos de Brachiaria brizantha e Brachiaria decumbens. Ciência Rural, v.36, n. 6, p.15401545, 2006.

Protocolado em: 09 abr 2013 Aceito em: 04 jun 2013 